\title{
Intelligent Control Frequency Microgrid in Islanded Mode by Central Protection Unit
}

Mojtaba Hajihosseini ${ }^{1}$, Ali Akbar Abedi ${ }^{1}$, Dariush Nakhaei ${ }^{1}$, Mohammad Hadi Hajihosseini ${ }^{2}$

${ }^{1}$ Department of Electrical Electronics Engineering, Islamic Azad University-Kazerun Branch, IRAN

${ }^{2}$ Department of Electrical Electronics Engineering, Islamic Azad University-Science and Research Branch, Fars, Iran.

Corresponding Author: Mojtaba Hajihosseini, Department of Electrical Electronics Engineering, Islamic Azad University-Kazerun Branch, IRAN

E-mail: mojtaba.hajihoseini@yahoo.com

\begin{abstract}
The appearance of microgrids created challenges such as microgrid protection and due to the presence distributed generation in microgrid network fault currents basically are variable.protection projects based on constant current must be upgraded.one of the major challenges, changes of microgrid frequency in islanded mode.in this paper a new protection system have provided to monitor microgrids and update current errors use extensive communication network. This system has been designed to respond to the dynamic changes in the system like connection/disconnection DG sources and changing microgrid user condition from connected network mode to islanded mode. the protection system Provided takes over control frequency microgrid in islanded mode and prevents microgrid instability. To control frequency central protection unit changes one of the distributed generators to busbar slack. Studies for the provided network sample have been done and show how the proposed protection system can run these models.
\end{abstract}

Keywords: Frequency control, smart microgrid, protection, fault currents, distributed generation, power system communication. 


\section{INTRODUCTION}

Given the recent developments in Power engineering technology and the growing concerns for global warning, the new tendency is to generate electricity from cleaner energy sources and closer to the consumption areas [1].Subsequently, power industry is inclined toward DG such as renewable energy source (RE) This also decreases the burden on transmission lines which already operate close to their limits [2], [3]. Microgrid is a collection of loud and small producers behaving like a citizen [4] from grid side thanks to intelligent control [5]. Although a microgrid consists of many producers and consumers, it works like a generator [6]. Micrigrids behave dynamically. At any time DG connection or disconnection may occur in microgrid. It occurs anytime, in production of electronic energy load sharing, and protection and control strategies will be incorrect. To operate properly microgrid parameters should follow any changes in microgrid [7], [8]. This requires a centralized management system which implements an algorithm to determine the structure of the system and yields the relay hierarchy at all branches of the network [9], [10]. Because two principles of traditional distribution network, radial structure network and passive nature,can no longer be valid [11]-[13]. In this case, a series of reforms in the system of the old protection is not enough and requires fundamental changes [14]-[16]. In [17] a novel microgrid protection system is proposed with extensive communication. The system reacts to using a network line under consideration and dynamic changes in system [18]. In [19] a stable control project of microgrids has provided in this project by using passing power, we diagnose microgrid islanded. Stabilizer units can reduce transients between generators. In [20] stabilization of different modes of short connection and microgrid have been discussed.
In this reference, the benefits of each connected method have to be examined.

Finally, microgrid performance and general network in connected mode have better stability than islanded performance. In the case of severe error by changing mode we can maintain the stable operation of the system and report the reliability of central unit the reliability.

In this paper, a protection system and smart control are provided that have the ability to protect network microgrid. This is an updated system, because compared to the previous proposed method it has high speed performance and the reliability is higher than the previous method.

This paper is organised as:

1) The proposed adaptive protection system is briefly stated.

2) Described microgrid modeling and central protection system.

3) Described microgrid frequency control in islanded mode.

4) Conclusion.

\section{PROPOSED PROTECTION SYSTEM WITH MICROGRID CENTRAL SECURITY}

Dynamic structure security. The communication system can be an Ethernet network based on TCP/IP. To isolate the errors, it is necessary to update relay operational current and current faults detection. MICROGRID CENTRAL PROTECTION UNIT continuously of microgrids and their adaptive operation develop conservation strategies. To connect with all relays and DG the proposed system requires microgrid central checks the status of DGs. In this model, DG status it is rated currents (IratedDGx) and shares of faults.

For a particular relay, the operating fault current (the current level that causes the relay to trip) is calculated as shown in (1): [21]

$$
\mathrm{I}_{\text {relay }}=\left(\mathrm{I}_{\text {faultGRID }} \times \text { Operating Mode }\right)+\sum_{\mathrm{i}=1}^{\mathrm{m}}\left(\mathrm{k}_{\mathrm{i}} \times \mathrm{I}_{\text {faultDGi }} \times \text { Status }_{\text {DGi }}\right)
$$


Where $\mathrm{m}$ is the total number of DGs in the microgrid, $\mathrm{Ki}$ is the impact factor of distributed generator on thefault current of the relay, and Ifault ${ }_{\mathrm{DGi}}$ and status are as described before. If the microgrid is operating in islanded mode, then the grid's fault contribution will be multiplied with the "Operating Mode" bit which will be equal to zero. Likewise, the fault contribution of a DG which is not in operation will be annulled by its status bit. The impact factor, namely $k$, is introduced to calculate the fault contribution of DGs at distant points in the microgrids. It takes a value between 0 and 1 and represents the decrease in the fault current due to inductance and resistance of low voltage distribution lines. The relays closer to the DG under consideration will have higher " $k$ " levels whereas those which are further downstream or upstream will have lower coefficients.

\section{MICROGRID MODELING AND CENTRAL PROTECTION SYSTEM}

Fig.1. shows a single line diagram of the distribution $13.8 \mathrm{kv}$ system for microgrid examination. The microgrid consists of a DG common unit (1.8 MVA) DG1 attached to feeder1, two units with electronic interface (EIDG): it means DG3 (2.5 MVA) and (1.5 MVA) DG2 are attached to feeders 3-4.

Unit DG1 is a unit with response (like a generator diesel) or a gas unit with the governor and excitation control system. DG2 and DG3 units are rapid control resource. It is assumed that the DG2 and DG3 both have the capacity to provide active and reactive power of the system. These 3 systems are used to investigate the possible interaction.

1) Between units (EI-DG).

2) Between units (EI-DG) and common units.

3) Between units DG and network.

Table.1. Loads parameters.

\begin{tabular}{|c|c|c|c|c|c|c|}
\hline Parameters & L1 & L2 & L3 & L4 & L5 & L6 \\
\hline Configuration & $\mathrm{Yg}$ & $\mathrm{Yg}$ & $\mathrm{Yg}$ & $\mathrm{Yg}$ & $\mathrm{Yg}$ & $\mathrm{Yg}$ \\
\hline $\begin{array}{c}\text { Nominal phase-to-phase } \\
\text { voltage Vn (Vrms) }\end{array}$ & 480 & 480 & 480 & 2400 & 2400 & 480 \\
\hline Nominal frequency fn (Hz) & 60 & 60 & 60 & 60 & 60 & 60 \\
\hline Active power P (W) & $0.9 \mathrm{e} 6$ & $1.5 \mathrm{e} 6$ & $1.5 \mathrm{e} 6$ & $1.21 \mathrm{e} 6$ & $0.6 \mathrm{e} 6$ & $1.21 \mathrm{e} 6$ \\
\hline $\begin{array}{c}\text { Inductive reactive power } \\
\text { QL (positive var) }\end{array}$ & $0.6 \mathrm{e} 6$ & $0.95 \mathrm{e} 6$ & $0.95 \mathrm{e} 6$ & $0.81 \mathrm{e} 6$ & $0.42 \mathrm{e} 6$ & $0.81 \mathrm{e} 6$ \\
\hline $\begin{array}{c}\text { Capacitive reactive power } \\
\text { Qc (negative var) }\end{array}$ & 0 & 0 & 0 & 0 & 0 & 0 \\
\hline
\end{tabular}

Table.2. Trans parameters.

\begin{tabular}{|c|c|c|c|c|c|}
\hline Parameters & $\mathrm{T}(\mathbf{a})$ & $T(b)$ & $T(c)$ & $T(d)$ & TL \\
\hline $\begin{array}{l}\text { Nominal power and frequency [ } \\
\text { Pn }(\text { VA }), f n(H z)]\end{array}$ & {$[15 \mathrm{e} 6,60]$} & {$[3 e 6,60]$} & {$[3 e 6,60]$} & {$[2 \mathrm{e} 6,60]$} & {$[1.25 \mathrm{e} 6,60]$} \\
\hline $\begin{array}{l}\text { Winding } 1 \text { parameters [ V1 Ph- } \\
\text { Ph(Vrms), R1(pu), L1(pu) ] }\end{array}$ & $\begin{array}{c}{[690000.0050} \\
0.0400]\end{array}$ & 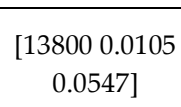 & 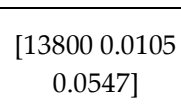 & $\begin{array}{c}{[138000.0021} \\
0.00109]\end{array}$ & $\begin{array}{c}138000.0035 \\
0.0300]\end{array}$ \\
\hline $\begin{array}{l}\text { Winding } 2 \text { parameters [ V2 Ph- } \\
\text { Ph(Vrms), R2(pu), L2(pu) ] }\end{array}$ & $\begin{array}{c}{[138000.0050} \\
0.0400]\end{array}$ & $\begin{array}{c}{[41400.0105} \\
0.0547]\end{array}$ & $\begin{array}{c}{[41400.0105} \\
0.0547]\end{array}$ & $\begin{array}{c}{[24000.0021} \\
0.00109]\end{array}$ & $\begin{array}{c}{[4800.0035} \\
0.0300]\end{array}$ \\
\hline Magnetization resistance $\mathbf{R m}(\mathrm{pu})$ & 500 & 500 & 500 & 500 & 500 \\
\hline Magnetization inductance Lm (pu) & 500 & 500 & 500 & 500 & 500 \\
\hline
\end{tabular}


Table.3. Data Maps in the Central Protection Unit.

\begin{tabular}{|c|c|c|c|}
\hline & Grid-Connected & Islanded & \\
\hline Operating Mode & 1 & 0 & \\
\hline $\begin{array}{c}\text { Grid Fault } \\
\text { Contribution }\end{array}$ & Ifault $_{\text {Grid }}$ & - & \\
\hline & & & \\
\hline Relays & $\begin{array}{c}\text { Operating Fault } \\
\text { Current }\end{array}$ & $\begin{array}{c}\text { Fault Detection } \\
(1-\mathrm{Y}, 0-\mathrm{N})\end{array}$ & $\begin{array}{c}\text { Time delay for } \\
\text { Selectivity }\end{array}$ \\
\hline R1 & $\mathrm{I}_{\mathrm{R} 1}$ & 1 & $\mathrm{t}_{1}$ \\
\hline $\mathbf{R} 2$ & $\mathrm{I}_{\mathrm{R} 2}$ & 1 & $\mathrm{t}_{2}$ \\
\hline $\mathbf{R} 3$ & $\mathrm{I}_{\mathrm{R} 3}$ & 0 & $\mathrm{t}_{3}$ \\
\hline $\mathbf{D G}_{\mathbf{s}}$ & Irated $_{\mathrm{N}}$ & Ifault $_{\mathrm{DGs}}$ & Status $(1-\mathrm{ON}, 0-\mathrm{OFF})$ \\
\hline $\mathbf{D G}_{\mathbf{1}}$ & $\mathrm{I}_{\mathrm{DG} 1}$ & Ifault $_{\mathrm{DG} 1}$ & 1 \\
\hline $\mathbf{D G}_{\mathbf{2}}$ & $\mathrm{I}_{\mathrm{DG} 2}$ & Ifault $_{\mathrm{DG} 2}$ & 1 \\
\hline $\mathbf{D G}_{\mathbf{3}}$ & $\mathrm{I}_{\mathrm{DG} 3}$ & Ifault $_{\mathrm{DG} 3}$ & 0 \\
\hline
\end{tabular}

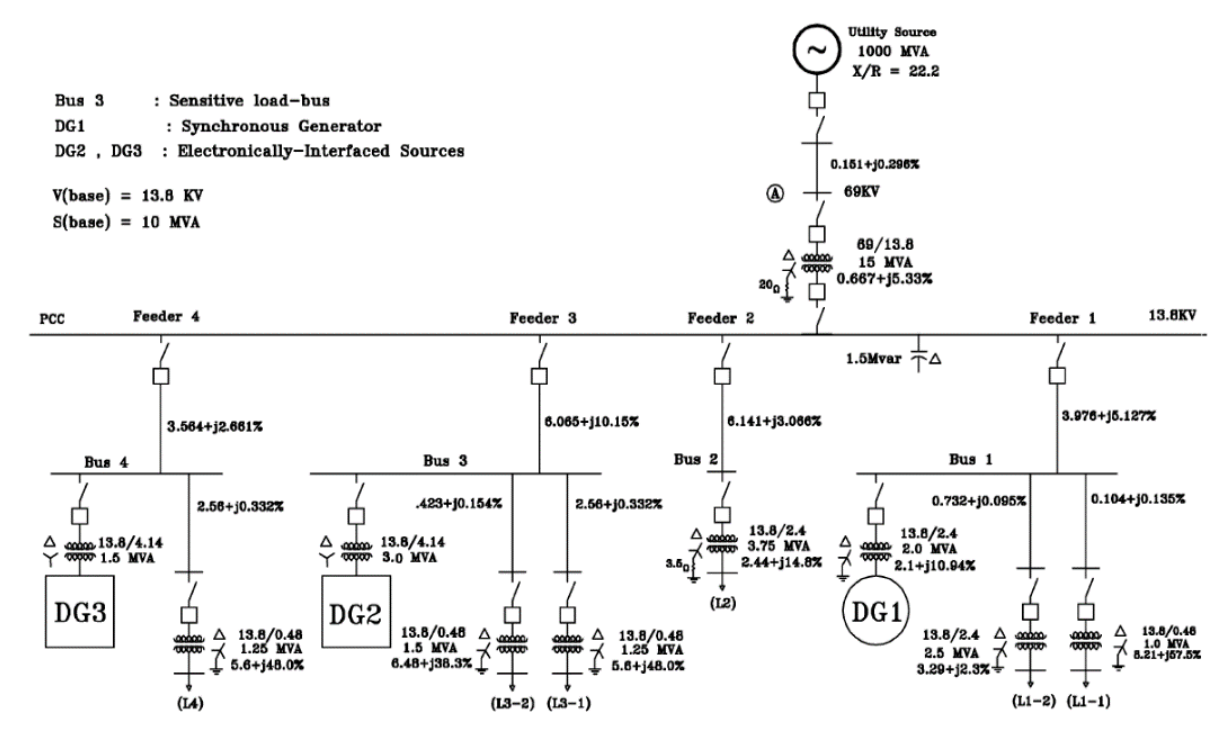

Fig.1. Single line diagram of microgrid under study of protection unit and central control.

\section{DESCRIBED MICROGRID FREQUENCY CONTROL IN ISLANDED MODE}

\subsection{CENTRAL PROTECTION ALGORITHM OF MICROGRID}

Microgrid central protection unit use an algorithm based on send and receive, when a message is received by microgrid central protection unit new error current in relay will be updated. To open separate connections relays are used when the current value exceeds the limit, relay sends a signal to adjust the error detection bit. If the error did not clear in another 
relay in delay time to open the circuit, that specific relay isolates the error. The time delay is set in the system to ensure appropriate selectivity. It is clear that central relays such as $\mathrm{R} 1$ and $\mathrm{R} 2$ have more delay than those on splits R4 and R8. Connection or disconnection in complicated system may change the structure of network and relay procedure. In this case relay rearrangement procedure may be required and time delay setting must be updated in current operational error, if any error occurred and was not resolved by supporting relay. Microgrid central protection unit and the task of identifying the error and sending orders to cut off realy. Is related to where the error is and automatically detects which should be a priority relay and which one should operate as a supporter.

\subsection{MICROGRID FREQUENCY CONTROL IN ISLANDED MODE}

If the microgrid is on connected mode, the network takes over the role of frequency control and the microgrid frequency is determined by the network but if the microgrid is in islanded mode, other network frequency is not microgrid frequency and one of generators must take over the role of frequency control.

It means that we must assume one of generators as busbar slack. In this proposed project we assume DG3 as a busbar slack. Speed sample will be sent to the control system DG3. There is a real power management block and control frequency for EI-DG units.
Local frequency is the input block and is speed sample when the microgrid is connected to the network, DG3 acts as busbar PQ and islanded mode should take over busbar slack role. In connected mode network takes over control frequency and microgrid so that microgrid remains stable in islanded mode. One of the DG resources must take over control frequency role and microgrid voltage.

By using Intelligent system and protection unit and central control, microgrid mode is diagnosed and to change control mode a signal is sent to DGs. When the microgrid turns to islanded mode to change control mode status to DGs, central protection unit sends a signal in which in this case, DG3 takes over voltage frequency control role in microgrid. Finally, frequency measurement entering the DG3 control system as microgrid frequency in islanded mode is controlled.

Fig.4. is shows an active power management and frequency control block diagram of a smart grid EI-DG unit. The input of this block diagram is local frequency $(\mathrm{Wn})$ that is estimated by PLL with bus voltages. The block diagram output is reference current of $x$ axis internal current controller that is contradicted with active power reference (P reference). Gain parameters of this block diagram are shown in table.5.

This structure is a reactive power strategy control based on voltage-droop characteristic that consists of a v-q characteristic to determine reactive power reference ( $Q_{\text {ref }}$ ) and PI controller to determine $\mathrm{q}$ axis reference current ( $\mathrm{i}_{\mathrm{qn}}$ (ref)). The block diagram input is rms voltage at the point of common coupling (PCC) of a DG unit.

Table.4. DGs role in both microgrid operational mode.

\begin{tabular}{|c|c|c|}
\hline Operating Mode Microgrid & Grid-Connected & Islanded \\
\hline $\mathbf{D G}_{\mathbf{s}}$ & Operating Mode & Operating Mode \\
\hline $\mathbf{D G}_{\mathbf{1}}$ & Shane PV & Shane PV \\
\hline $\mathbf{D G}_{\mathbf{2}}$ & Shane PQ & Shane PQ \\
\hline $\mathbf{D G}_{\mathbf{3}}$ & Shane PQ & Shane Slack \\
\hline
\end{tabular}




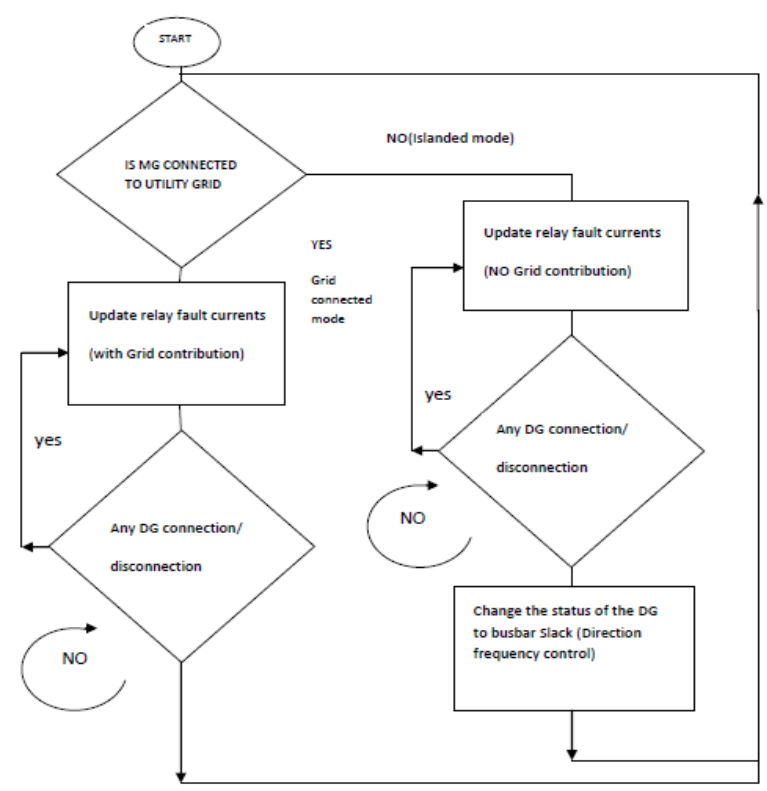

Fig.3. Central protection algorithm of microgrid.

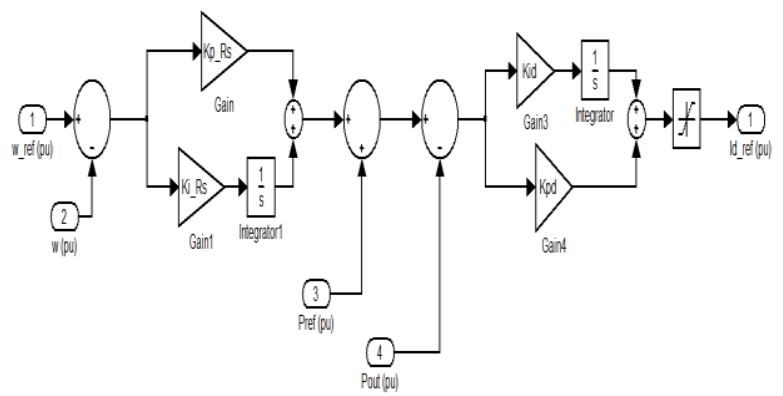

Fig.4. Block diagram of the frequency control.

Table.5. Gain parameters of frequency control scheme.

\begin{tabular}{|c|c|}
\hline Gain parameter & Value \\
\hline Kp_rs & 5 \\
\hline Ki_rs & 200 \\
\hline Kpd & 0.05 \\
\hline Kid & 30 \\
\hline Idn_max & 3 \\
\hline Idn_min & -3 \\
\hline
\end{tabular}

In $\mathrm{t}=0.6 \mathrm{~s}$ error occurs on network and network will be cut and MG turns islanded.

This is a scenario to show different aspects of protection project.

The system starts operation with a full load. DGs are (on) and MG operates in connected network.
Fig.5. shows relay current setting as a sample. As seen in this figure, by changing circuit to islanded mode the level of current setting is 
reduced which means that the term IfaultGrid is removed from equation.1.

It is a response to dynamic changes in system and shows system performance of central protection. If the proposed method is not used all relay current settings will remain stable in all scenarios.
Fig.6. microgrid frequency, shows network connected mode and islanded mode. It is seen that microgrid $\mathrm{t}=0.6 \mathrm{~s}$ changes to islanded mode and microgrid frequency will remain stable in both microgrid modes.

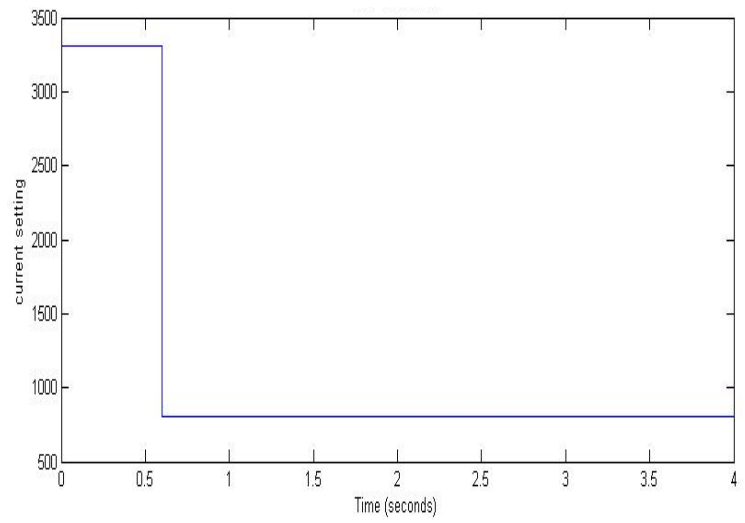

Fig.5. Load relay current setting (L3-1).

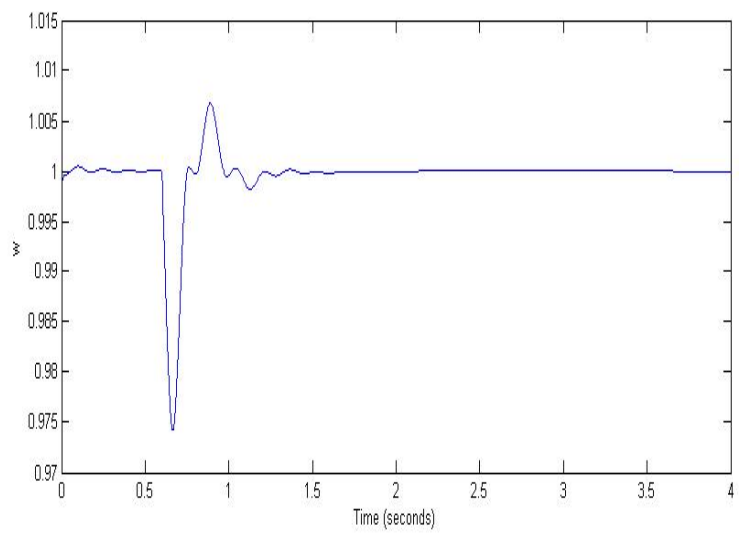

Fig.6. microgrid frequency in network connected mode and islanded mode in protection scenario.

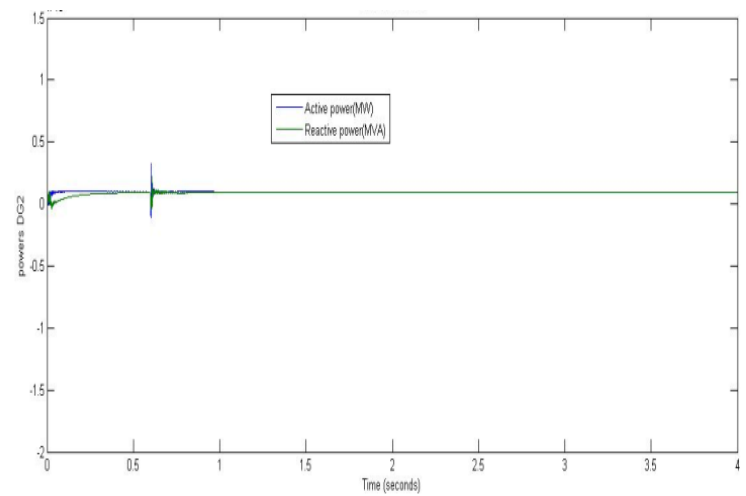

Figure(7)-power active and reactive of DG2 


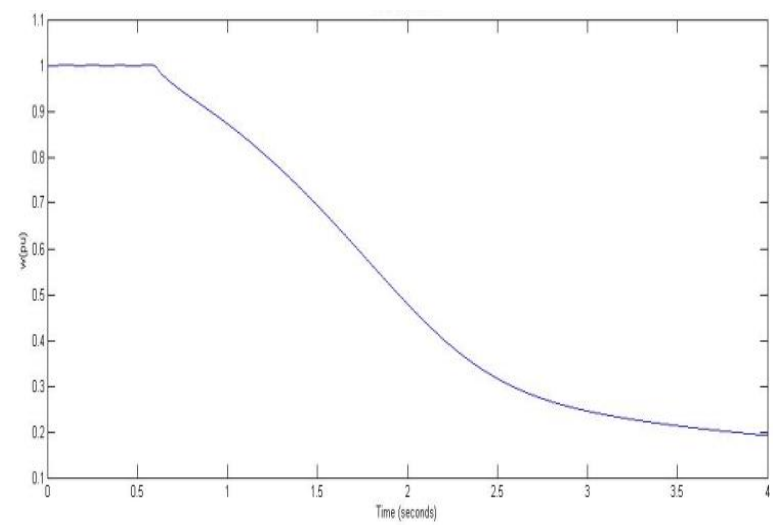

Figure(8)- microgrid frequency in network connected mode and islanded mode in protection scenario (Without control unit)

\section{CONCLUSION}

In this paper a novel protection system is provided for microgrids with DG high permeability. To monitor all endocrine equipment there is a central unit and new operation status is calculated for each received connection or disconnection by controller. Relay model and DG models are very versatile and can be used in different microgrid modeling. Regardless of their model and their producers, DGs global modeling, is important to have a global concept of DG connectivity.

\section{REFERENCES}

[1] C. M. Colson and M. H. Nehrir "A review of challenges to real-time power management of microgrids", Proc. IEEE Power \& Energy Society General Meeting (PES \'09), pp.1 -8 2009.

[2] G. K. B. Kroposki, R. Margolis, J. Torres, W. Bower, T. Key and D. Ton Renewable Systems Interconnection-Executive Summary,, 2009.

[3] J. Arai "Power electronics and its applications to renewable energy in Japan", IEEE Circuits Syst. Mag., vol. 8, pp.52 -66 2008.

[4] B. Lasseter "Microgrids", IEEE 2001 WM Panel, Role of Distributed Generation in Reinforcing the Critical Electric Power Infrastructure, 2001.
Implementing the concept of connection has a fundamental role in microgrid. To verify the proposed project maps of sample data on a predetermined scenario, They are simulated in MATLAB software. which highlights different aspects of the proposed protection projects. The obtained results show full protection in connected network and islanded mode and also stable frequency and voltage in islanded mode. The proposed project is flexible and can be developed in future projects.

[5] M. Barnes "Real-world microgrids-An overview", IEEE International Conference on System of Systems Engineering, 2007.

[6] B. Lasseter "Microgrids [distributed power generation]", Proc. IEEE Power Engineering Society Winter Meeting, vol. 1, pp.146 -149 2001.

[7] T. S. Ustun "Recent developments in microgrids and example cases around the world-A review", Renew. Sustain. Energy Rev., vol. 15, pp.4030 -4041 2011.

[8] J. Driesen "Protection issues in microgrids with multiple distributed generation units", Proc. Power Conversion Conf. (PCC \'07), pp.646 -653 2007.

[9] N. Hatziargyriou "Microgrids", IEEE Power Energy Mag., vol. 5, pp.78 -94 2007. 
[10] B. Kroposki "Making microgrids work", IEEE Power Energy Mag., vol. 6, pp.40 -53 2008.

[11] H. H. Zeineldin "Protective relay coordination for micro-grid operation using particle swarm optimization", Proc. 2006 Large Engineering Systems Conf. Power Engineering, pp.152 -157 2006.

[12] T. Loix "Protection of microgrids with a high penetration of inverter-coupled energy sources", Proc. 2009 CIGRE/IEEE PES Joint Symp. Integration of Wide-Scale Renewable Resources into the Power Delivery System, pp.1 $-62009$.

[13] X. Xialing and Z. Xiaoming "Overview of the researches on distributed generation and microgrid", Proc. Power Engineering Int. Conf. (IPEC 2007), pp.966 -971 2007

[14] J. I. Marvik "Analysis of fault detection and location in medium voltage radial networks with distributed generation", Proc. IEEE Power Tech, pp.1191 -1196 2007

[15] K. Maki "Protection planning development for DG installations", Proc. 20th Int. Conf. Exhib. CIRED 2009 Electricity Distribution-Part 1, pp.1 -4 2009

[16] E. J. Coster "Integration issues of distributed generation in distribution grids", Proc. IEEE, vol. 99, pp.28 -39 2011.

[17] T. S. Ustun "A microgrid protection system with central protection unit and extensive communication", Proc. 2011 10th Int. Conf. Environment and Electrical Engineering (EEEIC), 2011.

[18] T. S. Ustun "A central microgrid protection system for networks with fault current limiters", Proc. 2011 10th Int. Conf. Environment and Electrical Engineering (EEEIC), pp.1 -4 2011.

[19] Liu Zhengyi, Zeng Xiangiun, Tan Shuntao and Guo Zigang, "A Novel Scheme of Stability Control for Distributed Generation Systems," in Power System Technology. Power Con,Vol.2, pp: 1528- 1531, Nov.2004.

[20] K. Ragarnam and UK Hambarde, "Islanding and load shedding schemes for captive power plants," IEEE Transactions on Power Delivery, vol. 14, pp. 805-809, July 1999.

[21] Taha Selim Ustun, Cagil Ozansoy, and Aladin Zayegh, "Modeling of a Centralized
Microgrid Protection System and Distributed Energy Resources According to IEC 61850-7420," IEEE TRANSACTIONS ON POWER SYSTEMS, VOL. 27, NO. 3, AUGUST 2012.

[22] IEEE Std. 412.5-1992, "IEEE Recommended Practice for Excitation System Models for Power System Stability Studies", IEEE Power Engineering Society, 1992.

[23] C. A. Canizares ' Power Flow and Transient Stability Models of FACTS Controllers for Voltage and Angle Stability Studies" Proceedings of the 2000 IEEE winter Meeting, Singapore, January, 8 pages, 2000.

[24] Lin Wang, Helen Cheung, Alexander Hamlyn, Cungang Yang, Richard Cheung, "Network- Integrated Protection and Control Strategy for Power Distribution Systems" 2007 Large Engineering Systems Conference on Power Engineering,10-12 Oct. Page(s):39 $43,2007$.

[25] J. C. M. Vieira et al., "Performance of frequency relays for distributed generation protection," IEEE Trans. Power Del., vol. 21, pp.1120-1127, 2006. 